\title{
Descripción de la sintomatología asociada a fusariosis y comparación con otras enfermedades en gulupa (Passiflora edulis Sims.) en la región del Sumapaz (Colombia)
}

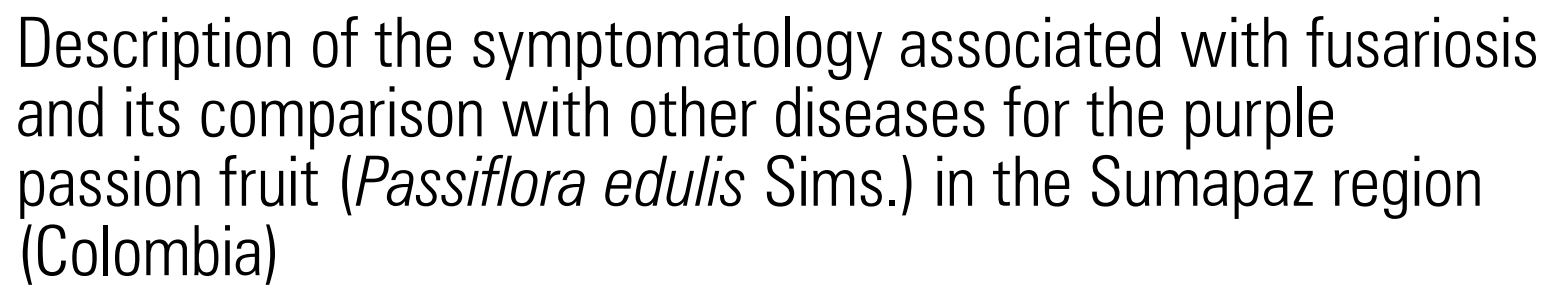

EMIRO ORTIZ C. ${ }^{1}$

LILLIANA M. HOYOS C. ${ }^{2,3}$

Planta sana de gulupa en fructificación; San Bernardo, Cundinamarca.

Foto: E. Ortiz C.

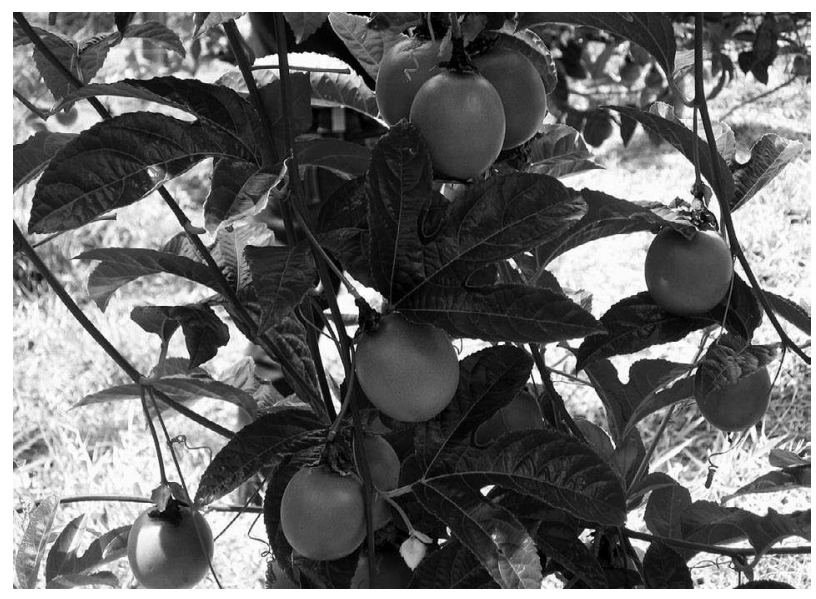

\section{RESUMEN}

Estudios encaminados a determinar la etiología de patologías relacionadas con fusariosis en el cultivo de gulupa en la región del Sumapaz (Colombia), indicaron la presencia de las enfermedades denominadas, marchitez por Fusarium y pudrición del cuello causadas por $F$. oxysporum y $F$. solani, respectivamente. El objetivo de la presente nota científica es describir la sintomatología asociada a las enfermedades mencionadas, haciendo una comparación con la sintomatología asociada a enfermedades causadas por bacterias y nematodos.

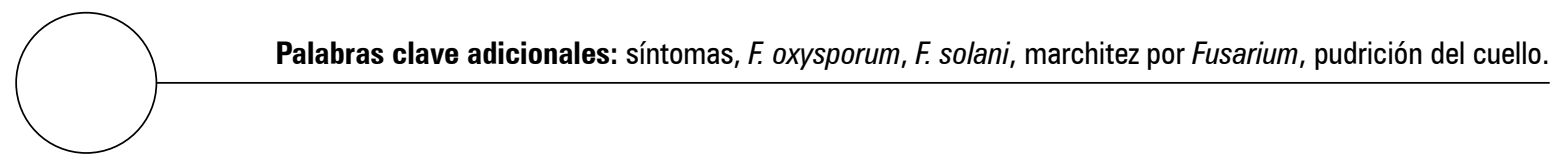

Facultad de Agronomía, Programa de Maestría en Ciencias Agrarias con énfasis en Fitopatología, Universidad Nacional de Colombia, Bogotá (Colombia).

2 Facultad de Agronomía, Departamento de Agronomía, Universidad Nacional de Colombia, Bogotá (Colombia).

3 Autor para correspondencia.limhoyosca@unal.edu.co 


\section{ABSTRACT}

Studies to determine the etiology of diseases related to fusariosis in passion fruit crops in the Sumapaz region of Colombia indicated the presence of Fusarium wilt and collar rot diseases caused by F. oxysporum and F. solani, respectively. The aim of this research was to describe the symptoms associated with the mentioned diseases and compare them with the symptoms associated with diseases caused by bacteria and nematodes.

Additional keywords: symptoms, F. oxysporum, F. solani, Fusarium wilt, collar rot.

Fecha de recepción: 09-04-2012

Aprobado para publicación: 29-05-2012

INTRODUCCIÓN

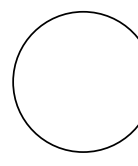

La gulupa (Passiflora edulis Sims.) es una planta originaria del sur de Brasil (Nakasone y Paull, 1998) perteneciente a la familia Passifloraceae (Ocampo et al., 2007). Es el tercer fruto de exportación en Colombia, después del banano y la uchuva, la cual se comercializa a través de exportadoras principalmente a países europeos entre los que se destaca Alemania.

El área cultivada ha aumentado significativamente en los últimos años, concentrándose en los departamentos del Huila, Valle del Cauca, Magdalena, Cundinamarca y Santander (Miranda et al., 2009). Recientemente el cultivo se extendió a Antioquia, Caldas, Boyacá, y Tolima, en lugares comprendidos entre 1.400-2.200 msnm (Guerrero y Hoyos, 2011). Sin embargo, el volumen de exportación, que manifestaba una tendencia al aumento en el año 2007, presentó un descenso para el año 2011 (Agronet, 2011).

Uno de los principales factores a considerar para esta tendencia es el efecto debido a la presencia de enfermedades. Entre las patologías reportadas en la región del Sumapaz (Colombia) se mencionan bacteriosis (Xanthomonas axonopodis y Stenotrophomonas maltophilia) (Benítez, 2010), virosis (SMV, CMV, CABMV) (Camelo, 2010), roña (Cladosporium cladoporioides sensu lato) (Riascos,
2011), enfermedades por nematodos (Meloidogyne sp.) (Moya, 2010), marchitez por Fusarium (F. oxysporum) y pudrición del cuello (F. solani) (Ortiz, 2012).

El proceso que llevó a la determinación de la etiología de las enfermedades asociadas a fusariosis en la gulupa, en la región del Sumapaz (Ortiz, 2012), incluyó en primera instancia la caracterización de la sintomatología presente en campo. Para esto, se realizaron muestreos entre junio de 2009 y octubre de 2010, en fincas localizadas en diferentes municipios de la región. En total se procesaron 56 muestras de las cuales un 35,7\% procedían de Tibacuy, 23,2\% de Venecia, 19,6\% de San Bernardo, 12,5\% de Granada, 3,6\% de Silvania y $5,4 \%$ de Pandi. Un $50 \%$ de las muestras se colectaron en época lluviosa y un $50 \%$ en época seca. Esto es un indicador del avance que han manifestado estas enfermedades en la zona del Sumapaz y su impacto epidemiológico en cualquier época climática. Para tal fin se tomaron muestras de plantas con síntomas de marchitez, clorosis, decoloración en haces vasculares, pudrición en cuello y defoliación.

Los síntomas se caracterizaron tanto en campo como en laboratorio. Para el análisis se realizaron cortes transversales y longitudinales de raíz, 
cuello, tallo y ramas, además de observaciones a simple vista y con ayuda del estereoscopio. Dicha caracterización arrojó correspondencia con la sintomatología descrita para pasifloráceas afectadas por marchitez por Fusarium (McKnight, 1953; Gardner, 1989; Ploetz, 1991; Ploetz, 2003; Fischer y Rezende, 2008) y pudrición del cuello (Ploetz, 1991; Cole et al., 1992; Ponte, 1993; Tamayo, 1999; Fischer et al., 2005; Ploetz, 2006).

A continuación se describen los síntomas de marchitez por Fusarium y pudrición del cuello encontrados en gulupa.

Marchitez por Fusarium: los síntomas iniciales son retraso en el crecimiento y clorosis leve de algunas hojas, la cual progresa hacia un grado moderado. El patrón de la clorosis es uniforme en toda la hoja (figura 1A). Posteriormente algunas ramas muestran marchitez y decoloración de los haces vasculares, los cuales se tornan de un tono rojizo (figura 1B). La enfermedad progresa con clorosis severa y marchitez hacia otras ramas (figura 1C). Eventualmente se presenta un enrojecimiento unilateral en el tallo o ramas principales, el cual se torna más oscuro hacia el centro de la lesión (figura 1D). En estados avanzados, en las raíces se manifiesta decoloración vascular y necrosis; en cuello y tallo, coloración rojiza de haces vasculares y necrosis con patrón de avance hacia la médula (figura 1E), de la cual en ciertos casos surge micelio. En la parte aérea se presenta una marchitez generalizada y defoliación severa. En algunos casos, es posible apreciar la presencia de frutos con rugosidades en diferentes estados de madurez que permanecen adheridos a la planta (figura 1F). Finalmente, ocurre necrosis y muerte de las plantas.

Pudrición de cuello: en estados iniciales se presenta decaimiento y clorosis de algunas ramas, acompañada de alteraciones en el cuello como pardeamiento o cuarteamiento de la corteza (figura 2A). Posteriormente, la enfermedad produce necrosis y marchitamiento en algunas ramas (figura 2B), pero sin cambios en la coloración de los haces vasculares (figura 2C); en el cuello se produce un chancro localizado que vira de color rojizo a café, el cual progresa desde la epidermis hacia la médula (figura 2D). Cuando la enfermedad llega a una etapa avanzada, las raíces manifiestan procesos necróticos, el cuello sufre una pudrición severa (figura 2E) con eventual formación de peritecios (figura 2F), en el tallo hay decoloración vascular que va adquiriendo coloración rojiza, la cual eventualmente se extiende a ramas. La necrosis del cuello y tallo puede llegar a alcanzar $20 \mathrm{~cm}$ de altura. En la parte aérea ocurre un marchitamiento generalizado asociado a defoliación, presencia de frutos con rugosidades en diferente estado de madurez adheridos a la planta y finalmente muerte de las plantas.

Para el aislamiento de Fusarium se hicieron cortes de explantes a nivel de raíz, tallo o rama, de lesiones en estados iniciales e intermedios de enfermedad. Un alto porcentaje de los aislamientos obtenidos de las muestras procesadas (67,9\%) correspondieron a Fusarium spp.

La caracterización morfológica macroscópica y microscópica mediante estándares internacionales (Leslie y Summerell, 2006) de los 20 aislamientos procesados permitió la identificación de $F$. oxysporum (14 aislamientos) y F. solani (5 aislamientos). La posterior identificación de los aislamientos por medio de marcadores biológicos y moleculares, respaldó la identificación por medio de marcadores morfológicos (Ortiz, 2012).

Finalmente la verificación de los postulados de Koch, a través de la realización de pruebas de patogenicidad confirmó la etiología de marchitez por Fusarium y pudrición del cuello, causados por F. oxysporum y F. solani, respectivamente (Ortiz, 2012)

\section{Comparación de las fusariosis con otras enfer- medades de la gulupa}

Según Benítez y Hoyos (2009), en marchiteces causadas por Xanthomonas, las hojas afectadas 


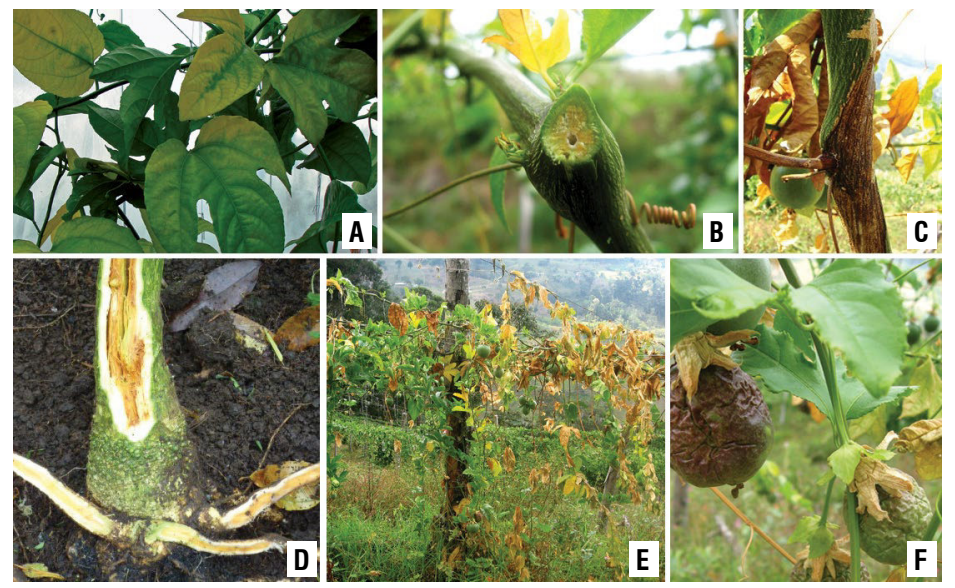

Figura 1. Sintomatología sugestiva de marchitez por Fusarium. A. hojas con patrón de clorosis uniforme, B. decoloración típica con enrojecimiento de haces vasculares en rama, C. enrojecimiento unilateral en tallo, D. decoloración de haces vasculares en cuello y tallo, E. hojas cloróticas, F. frutos con rugosidades adheridos a la planta. Fotos: A, B, D, E, F: E. Ortiz C.; C: R. Mora.
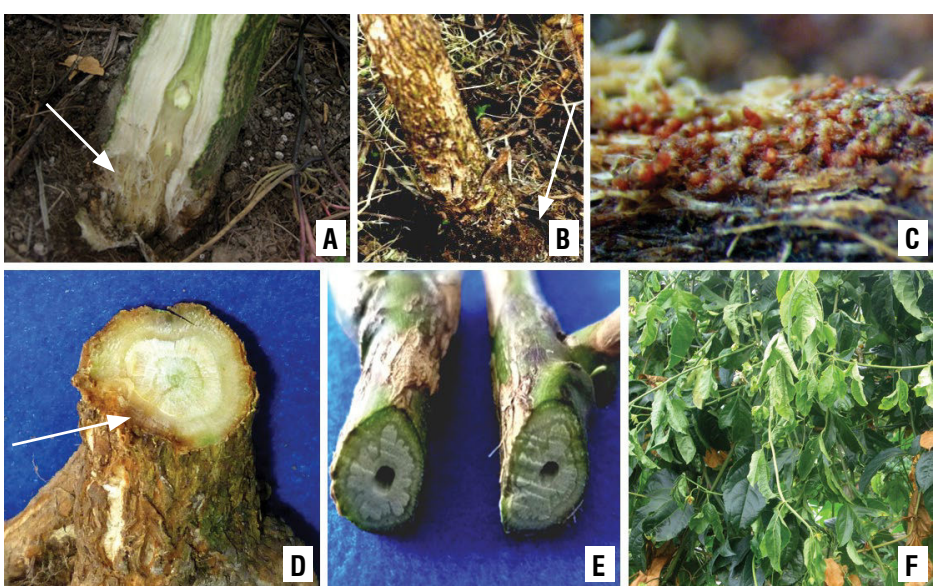

Figura 2. Sintomatología sugestiva de pudrición del cuello. A. pardeamiento leve en la base del cuello en planta con síntomas iniciales, B. pudrición severa en la base del cuello en planta con síntomas avanzados, $\mathrm{C}$. formación de peritecios correspondientes al teleomorfo Nectria haematococca sobre la lesión, D. formación de chancro con avance desde la epidermis hacia la médula, $E$. ramas sin decoloración en haces vasculares, F. clorosis, marchitez e inicio de necrosis en la parte aérea. Fotos: E. Ortiz C. 


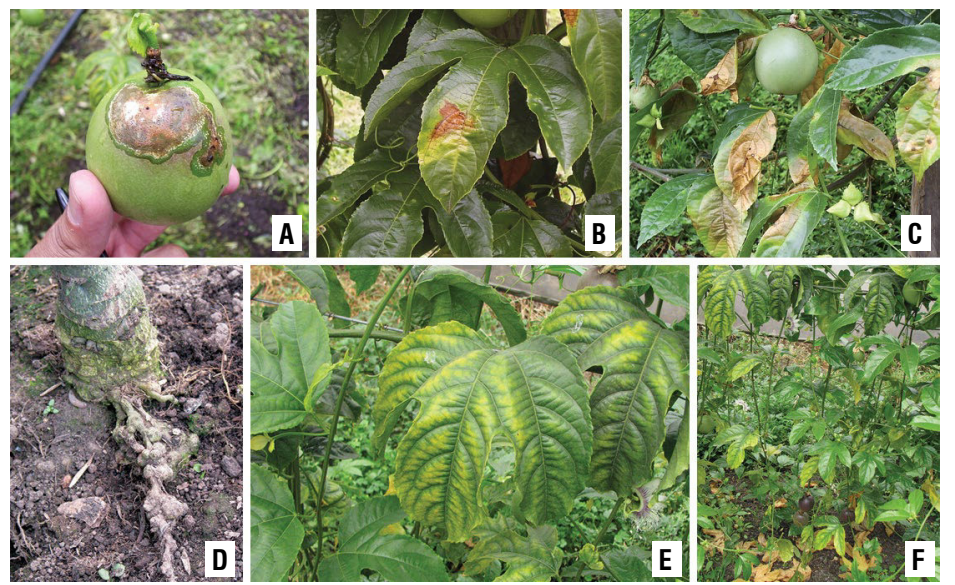

Figura 3. Sintomatología sugestiva de bacteriosis (A-C) y daño por nematodos (DF). A. mancha necrótica con exudado aceitoso en fruto, B. mancha foliar necrótica con exudado aceitoso, C. ramas con manchas necróticas típicas de bacteriosis, D. raíces con nódulos, E. clorosis intervenal, F. aspecto de la parte aérea con patrones de clorosis característicos causados por nematodos. Fotos: A-C: E. Guerrero; D-F: E. Ortiz C.

presentan halos aceitosos relacionados con degradación de cloroplastos, los síntomas prosiguen a manchas pardas y necróticas, con lesiones de aspecto aceitoso, presentándose inicialmente en algunas hojas, y luego extendiéndose a toda la planta; en tallos, frutos y zarcillos, el aspecto de las lesiones es similar a lo descrito en hoja (figuras 3A-C). Por otra parte, no se aprecia decoloración de haces vasculares, ni deshidratación de frutos, aunque sí marchitez general en estados avanzados y posterior defoliación.

Por su parte, las plantas afectadas por Meloidogyne sp., manifiestan a nivel foliar clorosis intervenal asociada a una textura coriácea. Hay detención del crecimiento (enanismo) y como consecuencia, las plantas tienen hojas y frutos más pequeños, afectando de forma considerable la producción (Moya, 2010). En raíces secundarias se pueden observar agallas, las cuales generan disrupción en su funcionalidad (figuras 3D-F). Como consecuencia de este trastorno, en épocas secas se manifiesta pérdida de turgencia generalizada y arrugamiento de los frutos por falta de agua.

Debido a que existe algún grado de similitud entre las sintomatologías asociadas a fusariosis, bacteriosis y nematodos, la tabla 1, aclara algunas de las diferencias a tener en cuenta para alcanzar una mayor aproximación en el diagnóstico inicial de campo.

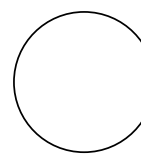

AGRADECIMIENTOS

Este trabajo forma parte el proyecto "Análisis epidemiológico y valoración económica de las principales enfermedades de la gulupa (Passiflora spp.)", financiado por el Ministerio de Agricultura y Desarrollo Rural, Asohofrucol y la Universidad Nacional de Colombia, sede Bogotá. También agradecemos a Solange Benítez y Eugenio Guerrero, por sus valiosos aportes. 
Tabla 1. Diferencias entre sintomatologías producidas por algunas enfermedades de la gulupa.

\begin{tabular}{|c|c|c|c|c|}
\hline \multirow[b]{2}{*}{ ÓRGANO } & \multicolumn{4}{|c|}{ ENFERMEDAD Y AGENTE CAUSAL } \\
\hline & $\begin{array}{l}\text { Marchitez vascular por } \\
\text { Fusarium (F. oxysporum) }\end{array}$ & $\begin{array}{l}\text { Pudrición del cuello } \\
\text { (F. solani) }\end{array}$ & $\begin{array}{l}\text { Mancha de aceite } \\
\text { (X. axonopodis y } S \text {. } \\
\text { maltophilia) }\end{array}$ & $\begin{array}{l}\text { Agalla de la raíz. } \\
\text { (Meloidogyne sp.) }\end{array}$ \\
\hline Raíz & $\begin{array}{l}\text { Retraso en el desarrollo, } \\
\text { presencia de puntos } \\
\text { necróticos. }\end{array}$ & $\begin{array}{l}\text { Retraso en el desarrollo, } \\
\text { necrosis en estados } \\
\text { avanzados. }\end{array}$ & No hay daño. & Formación de agallas². \\
\hline Cuello & $\begin{array}{l}\text { Coloración rojiza de haces } \\
\text { vasculares. En estado } \\
\text { avanzado necrosis que } \\
\text { llega hasta el tallo, con } \\
\text { eventual formación de } \\
\text { esporodoquios. }\end{array}$ & $\begin{array}{l}\text { Chancro que avanza } \\
\text { desde la epidermis a } \\
\text { la médula, en estado } \\
\text { avanzado desarrollo de } \\
\text { peritecios. }\end{array}$ & No hay daño. & No hay daño. \\
\hline Tallo y rama & $\begin{array}{l}\text { Al corte transversal se } \\
\text { aprecia decoloración con } \\
\text { enrojecimiento de haces } \\
\text { vasculares. Marchitez en } \\
\text { ramas. }\end{array}$ & $\begin{array}{l}\text { Al corte transversal } \\
\text { usualmente no se } \\
\text { aprecia decoloración } \\
\text { vascular. Marchitez en } \\
\text { ramas. }\end{array}$ & $\begin{array}{l}\text { Al corte transversal } \\
\text { no hay cambios en la } \\
\text { coloración. } \\
\text { En ramas procesos } \\
\text { necróticos asociados } \\
\text { a marchitez. Lesiones } \\
\text { necróticas puntuales } \\
\text { en tallos con halos } \\
\text { aceitosos'. }\end{array}$ & $\begin{array}{l}\text { Al corte transversal } \\
\text { no hay cambios en la } \\
\text { coloración. En algunas } \\
\text { ramas se aprecian } \\
\text { procesos necróticos y } \\
\text { marchitez. }\end{array}$ \\
\hline Hojas & $\begin{array}{l}\text { Clorosis ascendente con } \\
\text { un patrón generalizado en } \\
\text { la hoja. Defoliación. }\end{array}$ & $\begin{array}{l}\text { Clorosis ascendente con } \\
\text { un patrón generalizado } \\
\text { en la hoja. Defoliación. }\end{array}$ & $\begin{array}{l}\text { Manchas foliares o } \\
\text { manchas necróticas } \\
\text { con exudado aceitoso } \\
\text { de bordes indefinidos, } \\
\text { con halo aceitoso }{ }^{1} \text {. } \\
\text { Defoliación. } \\
\end{array}$ & $\begin{array}{l}\text { Clorosis intervenal } \\
\text { y textura coriácea. } \\
\text { Defoliación. }\end{array}$ \\
\hline Frutos & $\begin{array}{l}\text { Eventualmente presencia } \\
\text { de frutos arrugados } \\
\text { en diferente estado } \\
\text { de maduración, que } \\
\text { permanecen adheridos a } \\
\text { la planta. }\end{array}$ & $\begin{array}{l}\text { Eventualmente } \\
\text { presencia de frutos } \\
\text { arrugados en diferente } \\
\text { estado de maduración, } \\
\text { que permanecen } \\
\text { adheridos a la planta. }\end{array}$ & $\begin{array}{l}\text { Manchas aceitosas } \\
\text { superficiales en fruto, } \\
\text { dispersas y de bordes } \\
\text { irregulares, en estado } \\
\text { avanzado coleasen y } \\
\text { presentan exudado } \\
\text { aceitoso }{ }^{1} \text {. }\end{array}$ & $\begin{array}{l}\text { Presentan menor } \\
\text { tamaño }{ }^{2} \text {. Arrugamiento } \\
\text { en épocas secas }\end{array}$ \\
\hline
\end{tabular}

${ }^{1}$ Benítez (2010); ${ }^{2}$ Moya (2010).

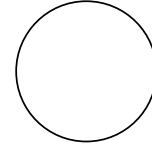

Agronet. 2011. Volúmenes exportados en gulupa entre 1991 y 2011. En: http://www.agronet.gov.co/ www/htm3b/ReportesAjax/VerReporte.aspx; consulta: noviembre de 2011.

Benitez, S. y L. Hoyos-Carvajal. 2009. Sintomatología asociada bacteriosis en zonas productoras de gulupa (Passiflora edulis Sims.) en Colombia. Rev. Colomb. Cienc. Hortíc. 3(2), 276-280.

\section{REFERENCIAS BIBLIOGRÁFICAS}

Benítez, S. 2010. Caracterización del agente etiológico de la enfermedad denominada "mancha de aceite" en cultivos de gulupa (Passiflora edulis Sims.) en zonas productoras de Colombia. Tesis de maestría. Facultad de Agronomía, Universidad Nacional de Colombia, Bogotá.

Camelo, V. 2010. Detección e identificación de los virus patógenos de cultivos de gulupa (Passiflora edulis 
Sims.) en la región del Sumapaz. Tesis de maestría. Facultad de Agronomía, Universidad Nacional de Colombia, Bogotá.

Cole, D.L., T.R. Hedges y T. Ndowora. 1992. A wilt of passion fruit (Passiflora edulis f. edulis Sims.) caused by Fusarium solani y Phytophthora nicotianae var. parasitica. Trop. Pest Manage. 38, 362-366.

Fischer, I.H. y J. Rezende. 2008. Diseases of passion flower (Passiflora spp.). Pest Technol. 2(1), 1-19.

Fischer, I.H., S.A. Lourenco, M.C. Martins, H. Kimati y L. Amorim. 2005. Seleção de plantas resistentes e de fungicidas para o controle da podridão do colo do maracujazeiro causada por Nectria haematococca. Fitopatol. Bras. 30, 250-258.

Gardner, D. 1989. Pathogenicity of Fusarium oxysporum f. sp. passiflorae to Banana Poka and other Passiflora spp. in Hawaii. Plant Dis. 73, 476-478.

Guerrero, E. y L. Hoyos. 2011. Buenas prácticas agrícolas (BPA) con énfasis en el manejo integrado de plagas y enfermedades de gulupa (Passiflora edulis Sims.). Produmedios, Bogotá.

Leslie, J.F y B.A. Summerell. 2006. The Fusarium laboratory manual. Blackwell Publishing Professional, Nueva York, NY.

McKnight, T. 1953. The woodiness disease of the passion vine. Queensl. J. Agr. Soc. 10, 4-35.

Miranda, D., G. Fischer, C. Carranza, S. Magnitskiy, F. Casierra-Posada, W. Piedrahita y L.E. Flórez (eds.). 2009. Cultivo, poscosecha y comercialización de las pasifloráceas en Colombia: maracuyá, granadilla, gulupa y curuba. Sociedad Colombiana de Ciencias Hortícolas, Bogotá.

Moya, J. 2010. Determinación de la incidencia e identificación de nematodos fitoparásitos en un cultivo comercial de gulupa Passiflora edulis Sims. Trabajo de grado. Universidad de Cundinamarca, Fusagasugá, Colombia.

Nakasone, H. y R.E. Paull. 1998. Tropical fruits. CAB Internacional, Wallington, U.K. pp. 270-291.

Ocampo, J., G. d'Eeckenbrugge, M. Restrepo, A. Jarvis, M. Salazar y C. Caetano. 2007. Diversity of Colombian Passifloraceae: biogeography and updated list for conservation. Biota Colomb. 8(1), 1-45.

Ortiz, E. 2012. Etiología de enfermedades asociadas a fusariosis en el cultivo de gulupa (Passiflora edulis Sims.) en la región del Sumapaz. Tesis de maestría. Facultad de Agronomía, Universidad Nacional de Colombia, Bogotá.

Ploetz, R.C. 2006. Fusarium-induced diseases of tropical, perennial crops. Phytopathol. 96, 648-652.

Ploetz, R.C. 1991. Sudden wilt of passion fruit in Southern Florida caused by Nectria haematococca. Plant Dis. 75, 1071-1073.

Ploetz, R.C. 2003. Diseases of tropical fruit crops. CABI Publishing, Wallingford, UK.

Ponte, J.J. 1993. As doenças do maracujá-amarelo no nordeste do Brasil. Rev. Bras. Frutic. 15, 11-14.

Riascos, D. 2011. Caracterización etiológica de la roña de la gulupa Passiflora edulis Sims. en la región del Sumapaz. Tesis de maestría. Facultad de Agronomía, Universidad Nacional de Colombia, Bogotá.

Tamayo, P. 1999. Estudios para el control de la secadera (Nectria haematococca Berk \& Br.) de la granadilla (Passiflora ligularis Juss.): Evaluación de patrones existentes y prácticas de manejo integrado. Corpoica, Rionegro, Colombia. 